\section{ОЦЕНКА КАЧЕСТВА СРЕДНЕГО ПРОФЕССИОНАЛЬНОГО ОБРАЗОВАНИЯ СТУДЕНТАМИ КОЛЛЕДЖА: СОЦИОЛОГИЧЕСКИЙ АСПЕКТ}

\begin{abstract}
Аннотация:
Статья посвящена анализу качества среднего профессионального образования с привлечением результатов авторских эмпирических исследований. Приводятся данные исследования, проведенного на базе нескольких организаций среднего профессионального образования города Екатеринбурга. Социологический анализ на основе комплексного подхода позволил выявить оценки и мнения непосредственных получателей образования относительно процессов, результатов и условий образования. Сделан вывод о доминирующей значимости результатов обучения для современного студента колледжа. В то же время возрастают требования к условиям обучения, в частности возникает потребность в комфортной и современной образовательной среде. При достаточно высокой оценке результатов образования (знаний, навыков) студенты дали низкие оценки условиям образования. Полученные данные схожи с данными других исследований, что свидетельствует о системных проблемах 6 организации образовательной среды в современном российском колледже и выявляет направления для совершенствования его деятельности.
\end{abstract}

Ключевые слова:

образование, качество образования, среднее профессиональное образование, студенты колледжа, оценка образования, процессы образования, результаты образования, условия образования, образовательная среда.

\section{QUALITY ASSESSMENT OF SECONDARY VOCATIONAL EDUCATION BY COLLEGE STUDENTS: A SOCIOLOGICAL ASPECT}

Summary:

The study analyzes the quality of secondary vocational education based on author's empirical studies findings. The paper presents the results of a survey conducted in several secondary vocational educational institutions in Yekaterinburg. Based on an integrated approach, a sociological analysis revealed the assessments and views of recipients of education in relation to educational processes, outcomes and learning conditions. It is concluded that educational outcomes are of primary importance to a modern college student. At the same time, the requirements to learning conditions are increased. In particular, there is a need for a comfortable and modern educational environment. Putting a high value on educational outcomes, the students have a low opinion of learning conditions. The data obtained are similar to other studies demonstrating systemic problems in the arrangement of the learning environment in modern Russian college and identifying areas for improvement in its activities.

Keywords: education, quality of education, secondary vocational education, college students, evaluation of education, educational processes, educational outcomes, learning conditions, learning environment.

Постановка проблемы и цели исследования. В последние годы заметно возрос интерес к вопросам социологического изучения качества среднего профессионального образования (далее СПО) [1]. Интерес исследователей обусловлен несколькими фракторами. Во-первых, во всем мире повышается значимость качества образования. Во-вторых, при заметном исследовательском интересе к качеству высшего образования тема качества СПО долго оставалась без внимания. Повышение роли среднего профессионального образования в конце первого десятилетия 2000-х гг. способствовало обращению исследователей к данной тематике. Как показывают практические наблюдения, качество СПО долгое время находилось на невысоком уровне и сегодня становится объектом совершенствования. В-третьих, в последние годы возрастает значимость мнений и оценок потребителей образовательных услуг, в том числе в системе СПО. Это акцентирует важность социологического мониторинга качества образования. Цель статьи - на данных эмпирии показать роль мониторинга качества СПО в построении системы управления качеством образования.

Обзор литературы. По вопросу оценки качества СПО в литературе [2] и имеющихся в открытом доступе материалах исследований [3] очевиден уклон в сторону маркетинговой парадигмы. Это означает, что качество образования понимается как соответствие ожиданиям потребителя, а потребители - это обучаемые, их родители, работодатели как заказчики выпускаемых специалистов, другие субъекты социума (органы власти, некоммерческие организации), заинтересованные в определенных параметрах выпускаемых специалистов среднего звена.

Таким образом, следует говорить о доминировании в научном дискурсе тенденции к пониманию качества образования как категории. При этом качество может быть измерено через субъективные мнения и оценки. Мы не склонны абсолютизировать данную позицию, поскольку считаем, что 
само понятие «образовательная услуга» не вполне применимо к системе образования. Образование подразумевает нечто большее, чем услугу: прежде всего это всестороннее развитие личности специалиста, а не просто подготовка кадров для рынка труда. Говоря о гуманизации образования, следует иметь в виду именно данный посыл, но он зачастую игнорируется в исследованиях современных ученых - социологов, педагогов. В связи с этим наиболее рациональным представляется комплексный подход к оценке качества образования, предполагающий оценку и процессов, и результатов образования [4], а мнение потребителя совмещается с другими значимыми технологиями и параметрами оценки. Мониторинг качества образования, следовательно, предполагает использование нескольких методов оценки, включая опрос субъектов СПО. Социологическая оценка образования как процесса и результата является основой проведения такого мониторинга.

Материалы и методы. Методом исследования в статье выступил анализ результатов эмпирических исследований, проведенных автором. Проведено анкетирование обучающихся колледжей города Екатеринбурга: Уральского колледжа бизнеса, управления и технологии красоты (ГБПОУ СО «УКБиТК»), Екатеринбургского колледжа транспортного строительства (ГАПОУ СО «ЕКТС») и Уральского политехнического колледжа - Межрегионального центра компетенций (ГАПОУ СО «УПК-МЦК»); N = 155. В выборке представлены студенты 2, 3 и 4-х курсов обучения. Девушки составили 82,8 \%, юноши - 17,2 \%. Инструментарием послужил опросник, состоящий из нескольких блоков вопросов. Согласно комплексной методологии исследования (качество СПО = качество процессов, качество результатов и качество условий), в единую схему объединены блоки вопросов относительно мнений и оценок студентами качества условий, процессов и результатов образования.

Основные результаты исследования. Согласно полученным результатам (табл. 1), большинство студентов высоко оценили качество преподавания как процесса и как условия образования. Более 80 \% респондентов выразили удовлетворенность основными параметрами преподавания: наиболее удовлетворены студенты параметрами «степень актуальности информации» (86,3 \%) и «степень доступности изложения материала» (81,3 \%). Наибольшие сомнения у студентов вызвал параметр оценки «степень соответствия информации требованиям профессии» (доля неудовлетворенных студентов - 5,9%). Это показывает, что опрошенные осознают важность соответствия преподаваемых предметов требованиям будущей профессии и проблематизируют данный аспект.

Таблица 1 - Распределение ответов респондентов на вопрос: «Оцените качество преподавания в Вашем колледже по следующим критериям»

\begin{tabular}{|l|c|c|c|}
\hline \multirow{2}{*}{ Вариант ответа } & \multicolumn{3}{|c|}{ Критерий, \% ответивших } \\
\cline { 2 - 4 } & $\begin{array}{c}\text { Степень } \\
\text { актуальности } \\
\text { информации }\end{array}$ & $\begin{array}{c}\text { Степень соответствия } \\
\text { информации требованиям } \\
\text { профессии }\end{array}$ & $\begin{array}{c}\text { Степень доступности } \\
\text { изложения материала }\end{array}$ \\
\hline Удовлетворен & 54,9 & 56,2 & 45,2 \\
\hline Скорее удовлетворен & 31,4 & 28,8 & 36,1 \\
\hline $\begin{array}{l}\text { В чем-то удовлетворен, } \\
\text { в чем-то не удовлетворен }\end{array}$ & 9,8 & 9,2 & 12,9 \\
\hline Скорее неудовлетворен & 3,3 & 5,9 & 5,2 \\
\hline Не удовлетворен & 0,7 & 0,0 & 0,6 \\
\hline
\end{tabular}

Достаточно высоко оценен процесс взаимодействия студентов с преподавателями. Прежде всего респонденты удовлетворены применением интерактивных фрорм работы на учебных занятиях (удовлетворенность выразили почти 80 \% студентов). В то же время отметим, что полностью удовлетворены этим параметром 53,9 \%, остальные выразили определенную степень сомнения. Возможно, это свидетельствует о том, что не все студенты знакомы с такими формами занятий и их ответы были призваны скрыть эту неосведомленность. В данном вопросе требуется детализация, что будет определенно учтено в будущих исследованиях. Параметры взаимодействия студентов с преподавателями были практически одинаково оценены студентами всех трех представленных образовательных организаций. В одной из них несколько более низко был оценен параметр «справедливость оценок знаний студентов», что представляет собой резерв для совершенствования качества образования в этом учреждении.

Несколько иная ситуация наблюдается в области организации учебного процесса, с точки зрения опрошенных студентов. Оценка параметров по данному критерию показала, что практически по каждому из них имеется резерв для совершенствования. Так, расписанием занятий выразили полную удовлетворенность лишь 17,5 \%, в то время как вовсе не удовлетворены 15,6 \%. Практически схожая ситуация наблюдается по параметру «недельный объем учебной нагрузки». 28,1 \% полностью удовлетворены наличием дополнительных курсов, фракультативов, консультаций, 5,9 \% - вовсе не удовлетворены. Только 38,1 \% студентов отметили, что полностью удовле- 
творены организацией производственной практики в процессе обучения. В целом результаты исследований показали, что от 5,2 до 7,8 \% студентов полностью не удовлетворены организацией учебного процесса в колледже.

Другим условием качества образования выступила материально-техническая оснащенность учебного процесса в колледжах. В данной области также имеются значительные резервы, что одинаково характерно для всех трех колледжей. Студенты отметили, что не вполне удовлетворены наличием и качеством компьютерной техники (полностью удовлетворены - 43,1 \%, вовсе не удовлетворены - 1,9 \%, скорее не удовлетворены - 10,3 \%). 36,4 \% респондентов выразили позитивное мнение об обеспеченности учебного процесса необходимой методической и учебной литературой (более 10 \% не удовлетворены). 36,1 \% отметили, что их полностью устраивает оснащенность специализированных аудиторий для занятий по профессиональным дисциплинам и практикам (более $13 \%$ не удовлетворены). Наименьшую степень удовлетворенности опрошенные выразили по параметру оценки «наличие доступа к сети Интернет»: лишь 26,5 \% выразили полную удовлетворенность состоянием этого параметра качества СПО.

Отметим, что дифференциация студентов на успевающих/мотивированных на получение образования и неуспевающих/немотивированных может дать дополнительную информацию в вопросах совершенствования качества СПО. Студенты - субъекты образования, проявляющие активность в обучении и стремление к получению знания, профессиональных навыков, по-видимому, должны являться основной группой, на мнение которой следует опираться при анализе данных подобного мониторинга. В дальнейшем анализе результатов исследования мы планируем провести подобную диффреренциацию.

Социально-бытовые условия образовательной среды - немаловажный компонент качества СПО. Современный студент выбирает место своей учебы не только исходя из целесообразности получаемой профессии, но и учитывая комфортность среды обучения, обстановки и дизайна учебного и внеучебного образовательного пространства. Результаты исследований показали, что именно по данному критерию качества СПО наблюдаются наиболее проблемные оценки (табл. 2).

Таблица 2 - Распределение ответов респондентов на вопрос: «Оцените качество социально-бытовой инфраструктуры в Вашем колледже по следующим критериям»

\begin{tabular}{|l|c|c|c|c|c|}
\hline \multirow{2}{*}{ Вариант ответа } & \multicolumn{4}{|c|}{ Критерий, \% ответивших } \\
\cline { 2 - 6 } & $\begin{array}{c}\text { Состояние } \\
\text { и работа } \\
\text { студенческого } \\
\text { общежития }\end{array}$ & $\begin{array}{c}\text { Работа } \\
\text { столовой, } \\
\text { бурета }\end{array}$ & $\begin{array}{c}\text { Территория } \\
\text { колледжа }\end{array}$ & $\begin{array}{c}\text { Места } \\
\text { общественного } \\
\text { пользования }\end{array}$ & $\begin{array}{c}\text { Аудитории } \\
\text { колледжа }\end{array}$ \\
\hline Удовлетворен & 11,6 & 22,9 & 34,6 & 20,8 & 34,0 \\
\hline Скорее удовлетворен & 19,0 & 26,1 & 24,2 & 23,4 & 30,1 \\
\hline $\begin{array}{l}\text { В чем-то удовлетворен, } \\
\text { в чем-то не удовлетворен }\end{array}$ & 26,4 & 34,0 & 21,6 & 26,0 & 22,9 \\
\hline Скорее неудовлетворен & 24,8 & 13,1 & 15,7 & 19,5 & 10,5 \\
\hline Не удовлетворен & 18,2 & 3,9 & 3,9 & 10,4 & 2,6 \\
\hline
\end{tabular}

Согласно анализу ответов респондентов, руководство колледжей недостаточно внимания уделяет вопросам обустройства социально-бытового пространства образования, по-видимому считая, что эти условия являются вторичными и неважными. Мнения студентов опровергают данный подход. Очевидно, что по критерию социально-бытовых условий качество образования нуждается в оптимизации.

Блок анализа «качество - результат» представлен рядом вопросов анкеты, связанных с приобретаемыми знаниями и навыками. В целом степень удовлетворенности по данному критерию очень высока. Студенты достаточно высоко оценили уровень получаемых знаний и навыков по профессиональным модулям: более 50 \% полностью удовлетворены данным параметром, 26,5 \% - скорее удовлетворены, вовсе не удовлетворенных не выявлено. Также достаточно высоки оценки опрошенных по параметру «общеобразовательные дисциплины»: 40,9 \% полностью удовлетворены, 37,0 \% скорее удовлетворены, не удовлетворены - менее 1 \%. Наименее высока оценка респондентов по параметру «компьютерные технологии»: 44,4 \% выразили полную удовлетворенность знаниями и навыками, получаемыми в данной области, 2,6 \% - крайнюю неудовлетворенность.

Полученные результаты позволяют заключить, что уровень преподавания общеобразовательных, профессиональных дисциплин, физической культуры, иностранных языков является вполне высоким. В то же время уровень преподавания в области знаний высоких технологий, компьютерных знаний отстает от потребностей студентов колледжей. Необходимость серьезной 
подготовки студентов в области инфокоммуникационных технологий диктуется требованиями современного рынка труда и общества в целом. Как показали результаты исследований, в колледжах отсутствуют современное техническое обеспечение, оборудованные компьютерные классы, повсеместный доступ в интернет, что свидетельствует об отставании современной системы колледжского образования от требований времени. Традиционные технологии обучения уже не могут обеспечить подготовку высококлассных специалистов среднего звена: необходимы инновационные технологии. Отметим, что данная ситуация примерно схожа во всех трех обследованных организациях.

Другой немаловажный критерий качества СПО - условия для занятий обучаемых научноисследовательской деятельностью. Включенность студентов в НИРС обеспечивает связь науки и образования, позволяет поднять уровень профессиональной подготовки посредством проектной творческой деятельности, проводить профориентационную работу с обучаемыми. Почти 43 \% студентов отметили, что принимают участие в НИРС (в том числе 11,6 \% занимаются ею регулярно и не один год). Считаем, это очень высокий положительный показатель. Кроме того, среди студентов имеется и значительный потенциал: 40,1% опрошенных отметили, что заинтересованы и планируют заниматься НИРС. Очевидно, что необходима планомерная работа по привлечению этих студентов к НИРС, в том числе через популяризацию научного знания в доступных и игровых формах. Наибольшая доля увлеченных исследовательской и проектной деятельностью (12,8 \%) обнаружена среди студентов Уральского колледжа бизнеса, управления и технологии красоты, что свидетельствует о высоком уровне организации НИРС в этом колледже.

Учитывая, что основным требованием современных работодателей к выпускникам колледжей является наличие не только профессиональных знаний и навыков, но и опыта работы по профессии, важно зафиксировать, что более 20 \% студентов уже практикуют работу на постоянной основе. У 27 \% работающих (работавших) студентов работа полностью или частично соответствовала будущей специальности. Это положительный фрактор профессионализации студентов уже в период их обучения в колледже. Он свидетельствует об осознанности выбора будущей профессии студентами, с одной стороны, и о готовности работодателя принимать на работу еще не дипломированного специалиста - с другой. Уровень трудоустройства по профессии примерно одинаков у студентов различных обследованных колледжей. В целом же уверенно ориентированы на трудоустройство по специальности (диагностировалось при помощи вопроса: «Пригодятся ли Вам в будущем полученные в колледже профессиональные знания?») менее половины студентов (44 \%), остальные выразили сомнения на этот счет. Полагаем, это сигнализирует о наличии сложностей с трудоустройством в выбранной сфере выпускников некоторых направлений подготовки, например «Банковское дело». Практика показывает, что, действительно, выпускники этого направления часто трудоустраиваются не по специальности.

В целом качество образования в обследованных колледжах оценено студентами скорее на «4» - так ответили 57,2 \% респондентов. Оценку «5» дали 21,7 \% студентов, «3» - 18,6 \%, «2»2,6 \%. Наиболее высоко качество образования оценили студенты Уральского колледжа бизнеса, управления и технологии красоты.

Выводы. Анализ результатов авторского исследования позволил выявить положительные и сдерживающие моменты в качестве СПО, раскрыть потенциал мнений студентов в развитии качества образования в совокупности процессов, результатов и условий в рамках комплексного подхода. Установлено, что наиболее высоко студенты ценят результат образования и реальное состояние параметров отвечает их ожиданиям: результаты обучения были оценены максимально в сравнении с процессами и условиями. Наиболее неоднозначные и наименее высокие оценки получил компонент условий образования. Неудовлетворенность студентов вызвали такие его параметры, как компьютерное и иное материально-техническое обеспечение, обеспеченность учебной и методической литературой, организация производственной практики, социально-бытовые условия и т. д. Полученные результаты подтверждаются также данными других исследований [5]. Достаточно высока удовлетворенность студентов качеством процессов образования, что проявилось в оценке таких параметров, как взаимодействие с преподавателями и интерактивная составляющая образования. Вместе с тем и по данным параметрам можно фиксировать наличие проблемных звеньев. Социологический мониторинг призван содействовать их выявлению и дальнейшей оптимизации.

\section{Ссылки:}

1. Богачева Е.С. Среднее профессиональное образование : автореф. дис. ... канд. социол. наук. Новочеркасск, 2011. 19 с. ; Качество подготовки специалистов для сферы сервиса: социологический анализ : монография / под общ. ред. Р.А. Костина, Л.И. Геращенко. СПб., 2010. 143 с. ; Ковлякова В.Е. Оценка качества среднего профессионального образования в рамках государственного контроля : дис. ... канд. пед. наук. М., 2013. 209 с. 
2. Александров А.Е., Лисов В.И. Новый этап развития начального и среднего профессионального образования города Москвы. М., 2004. 36 с. ; Белоцерковский А.В. О «качестве» и «количестве» образования // Высшее образование в России. 2011. № 4. С. 3-9 ; Качество подготовки специалистов для сферы сервиса ... ; Стребкова Н.В. Социологический аспект проблемы оценки качества образования // Вестник Поволжского института управления. 2008. № 2. С. $176-182$.

3. Мониторинг деятельности ПОО. Социологические исследования [Электронный ресуpc]. URL: http://www.krirpo.ru/activity-2/monitoring/sotsiologicheskie-issledovaniya/ (дата обращения: 17.03.2017) ; Отчет о научно-исследовательской работе Российского государственного профессионально-педагогического университета [Электронный ресурc]. URL: http://monitoring.rsvpu.ru/ (дата обращения: 17.03.2017) ; Социологический мониторинг качества среднего профессионального образования в Санкт-Петербурге / под ред. Р.А. Костина, Е.В. Шишкиной. СПб., 2016. 171 с. ; Шуклина Е.А. Отчет о социологическом исследовании «Мониторинг качества образовательных услуг учреждений среднего профессионального образования, подведомственных министерству культуры и туризма Свердловской области» [Электронный ресурc]. URL: http://mkso.ru/data/File/itogovii\%20otchet\%20spo.pdf (дата обращения: 17.03.2017).

4. Субетто А.И. Государственная политика качества высшего образования: концепция, механизмы, перспективы [Электронный ресурc]. URL: http://www.trinitas.ru/rus/doc/0012/001a/00120196.htm (дата обращения: 02.06.2017); Godfrey T. How Should Quality of Education Be Re-Defined for Education Achievements in Tanzania? What Are Stakeholders' Opinions? // Journal of International Education and Leadership. 2013. Vol. 3, iss. 1. P. 1-7.

5. Мониторинг деятельности ПОО ...; О Отчет о научно-исследовательской работе ...; Социологический мониторинг ... ; Шуклина Е.А. Указ. соч.

\section{References:}

Aleksandrov, AE \& Lisov, VI 2004, A new stage in the development of primary and secondary vocational education in the city of Moscow, Moscow, 36 p., (in Russian).

Belotserkovsky, AV 2011, 'Concerning the quality and quantity of education', Vyssheye obrazovaniye v Rossii, No. 4, pp. 39, (in Russian). sian). Bogacheva, ES 2011, Secondary vocational education, Novocherkassk, PhD thesis abstract, Novocherkassk, 19 p., (in Rus-

Godfrey, T 2013, 'How Should Quality of Education Be Re-Defined for Education Achievements in Tanzania? What Are Stakeholders' Opinions?', Journal of International Education and Leadership, Vol. 3, iss. 1, pp. 1-7.

Kostin, RA \& Gerashchenko, LI (eds.) 2010, The quality of training specialists for the service sector: a sociological analysis, monograph, St. Petersburg, 143 p., (in Russian).

Kostin, RA \& Shishkina, EV (eds.) 2016, Sociological monitoring of the quality of secondary vocational education in St. Petersburg, St. Petersburg, 171 p., (in Russian).

Kovlyakova, VE 2013, Assessment of the quality of secondary vocational education within the state control, PhD thesis, Moscow, 209 p., (in Russian).

Shuklina, EA 2018, Report on the sociological research on monitoring of the quality of educational services of secondary vocational educational institutions subordinate to the Ministry of Culture and Tourism of the Sverdlovsk region, viewed 17 March 2017, <http://mkso.ru/data/File/itogovii\%20otchet\%20spo.pdf>, (in Russian).

Strebkova, NV 2008, 'Sociological aspect of the problem of assessing the quality of education', Vestnik Povolzhskogo instituta upravleniya, No. 2, pp. 176-182, (in Russian).

Subetto, Al 2017, State policy of the quality of higher education: concept, mechanisms, prospects, viewed 02 June 2017 , <http://www.trinitas.ru/rus/doc/0012/001a/00120196.htm>, (in Russian). 